\title{
Acute hypertensive encephalopathy presenting with a partial third nerve palsy: image findings
}

\author{
James W Ryan, ${ }^{1}$ Christine McCarthy, ${ }^{2}$ Sean Murphy, ${ }^{3}$ Eoin Kavanagh ${ }^{3}$
}

${ }^{1}$ Department of Radiology, Mater Misericordiae University Hospital, Dublin, Ireland ${ }^{2}$ Mater Misericordiae University Hospital, Dublin, Ireland ${ }^{3}$ Department of Geriatrics, Mater Misericordiae University Hospital, Dublin, Ireland

\section{Correspondence to} Dr James W Ryan, jamesryannchd@gmail.com

\section{Accepted 18 October 2016}

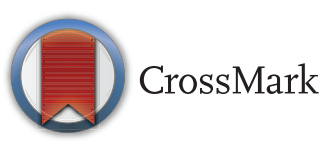

To cite: Ryan JW, McCarthy C, Murphy S, et al. BMJ Case Rep Published online: [please include Day Month Year] doi:10.1136/bcr-2016217520

\section{DESCRIPTION}

A middle-aged patient presented with partial third nerve palsy with pupillary sparing; the time of onset was unclear. A collateral history revealed that the patient had suffered gradual memory

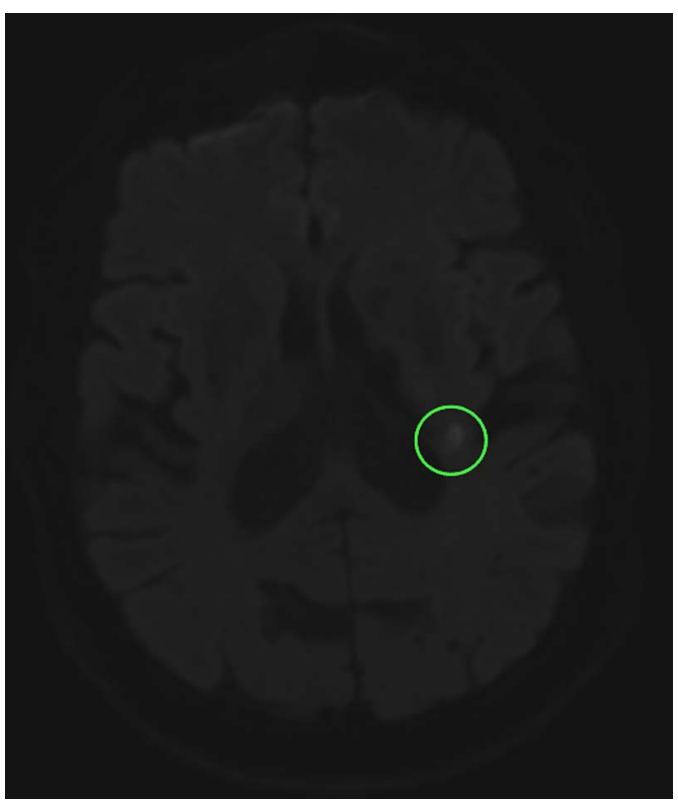

Figure 1 B1000 sequence: focal high signal in the periventricular white matter on the left.

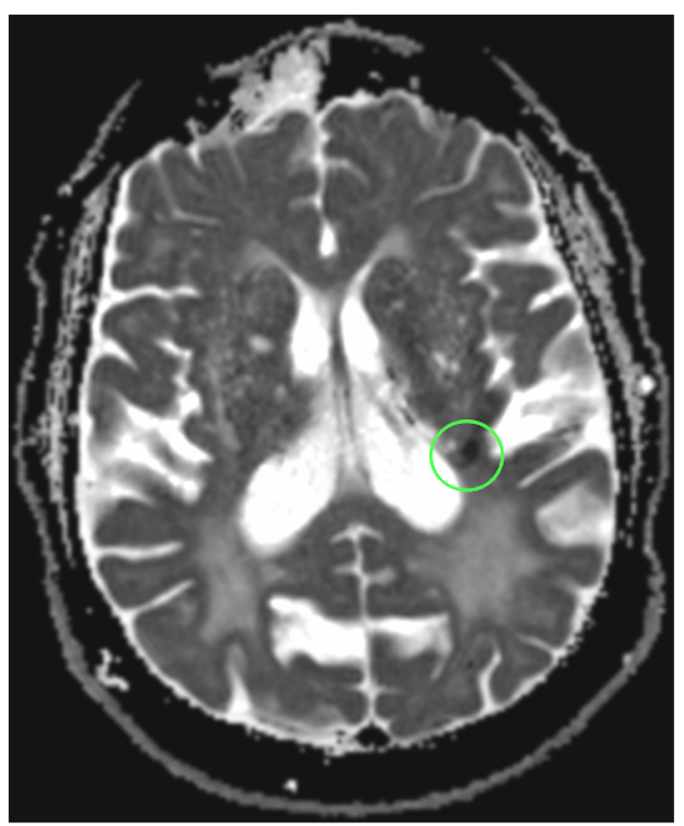

Figure 2 Apparent diffusion coefficient map: corresponding focal low signal in the periventricular white matter on the left. impairment, difficulty performing tasks and word finding problems in the preceding months.

The patient's blood pressure on admission was 210/140 mm Hg; subsequently malignant hypertension was diagnosed. There was no significant medical history and the patient did not take any prescription medications. There was a family history of stroke.

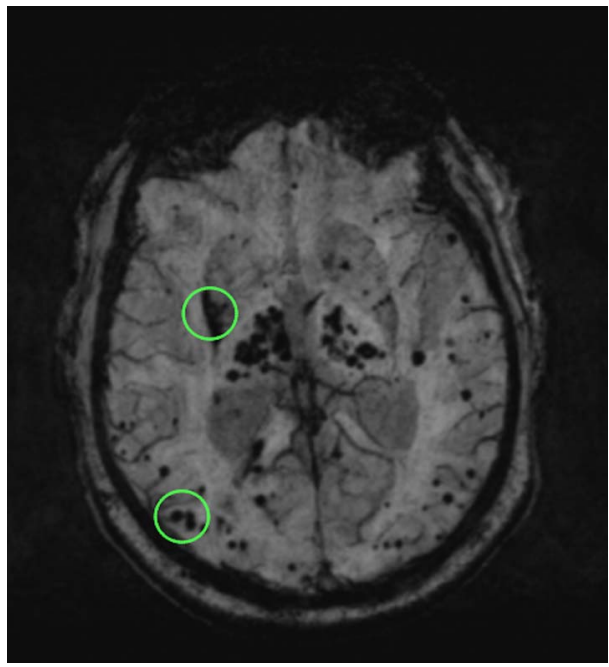

Figure 3 Susceptibility weighted sequence: diffuse multifocal low signal in keeping with punctate haemorrhages. Right posterolateral lentiform nucleus haemorrhage highlighted anteriorly. Subcortical right occipital lobe haemorrhage highlighted posteriorly.

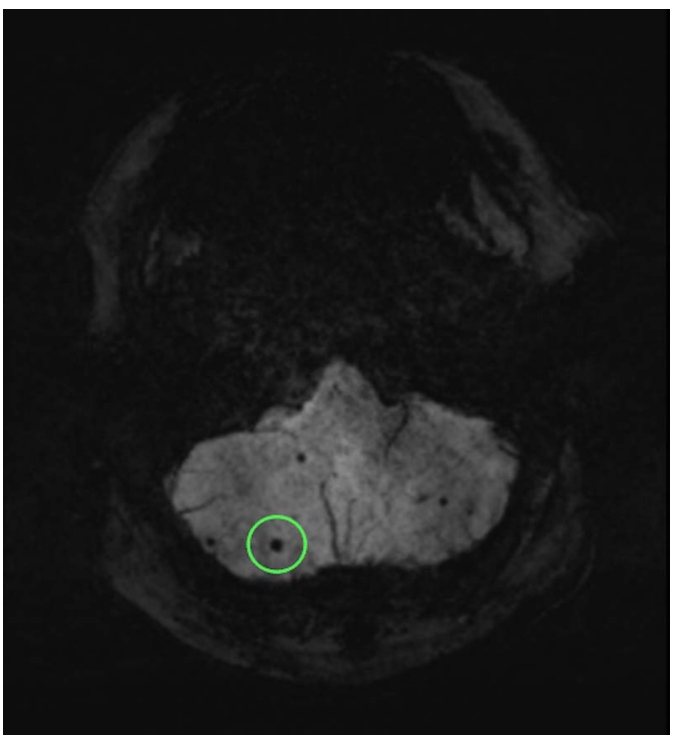

Figure 4 Susceptibility weighted sequence: multifocal areas of artefact secondary to punctate cerebellar haemorrhages. 


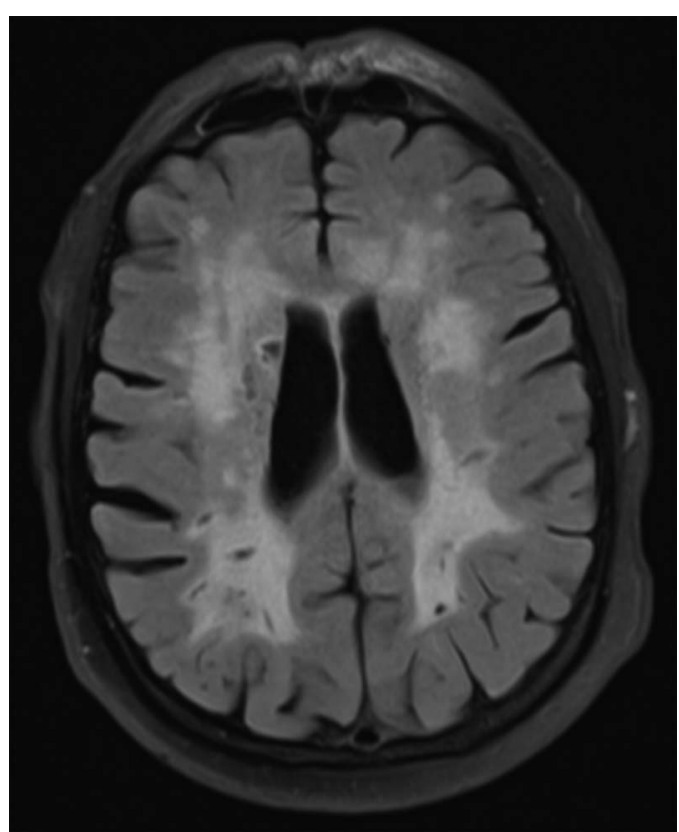

Figure 5 Flair sequence: confluent periventricular white matter high signal.

On examination there was partial third nerve palsy, pupils were equal and reactive to light. Exophthalmos was evident bilaterally. Tone was mildly increased symmetrically, in the upper and lower limbs. There was central obesity.

An MRI of the brain showed patchy foci of acute ischaemic change throughout the cerebrum with associated restricted diffusion (figures 1 and 2). There were multifocal small parenchymal haemorrhages in the basal ganglia, cerebellum and cerebral cortex (figures 3 and 4). These findings were consistent with an acute hypertensive encephalopathy, which is known to predominantly affect the posterior white matter and may also affect the basal ganglia and cerebellum as in this case. ${ }^{1}$ Confluent flair intense signal was also noted in the periventricular white matter (figure 5) in keeping with longstanding hypertension and subsequent small vessel disease.

Following early management with an intravenous glyceryl trinitrate infusion, this man was started on statin and three separate antihypertensive medications prior to discharge. Aspirin was not started in this case due the microhaemorrhages diagnosed on MRI.

\section{Learning points}

A recent 12-year retrospective study in an American hospital found that the number of patients presenting with hypertensive encephalopathy has risen dramatically since $2007 .^{2}$

- The clinical presentation of acute hypertensive encephalopathy is often variable and non-specific but the radiological findings are consistent. ${ }^{3}$

- MRI is more accurate than CT scan in the diagnosis of acute hypertensive encephalopathy. ${ }^{1}$

Contributors JWR is the corresponding and primary author. CM participated in literature review. SM is the specialist Stroke Consultant, who selected images for inclusion. EK is the senior author.

Competing interests None declared.

Provenance and peer review Not commissioned; externally peer reviewed.

\section{REFERENCES}

1 Ngow HA, Wan Khairina WM, Hamidon BB. An unsual finding of brain magnetic resonance imaging in a hypertensive patient. Neurol Int 2009;1:e3.

2 Polgreen LA, Suneja M, Tang F, et al. Increasing trend in admissions for malignant hypertension and hypertensive encephalopathy in the United States. Hypertension 2015;65:1002-7

3 Schwartz RB. Hyperperfusion encephalopathies: hypertensive encephalopathy and related conditions. Neurologist 2002;8:22-34.

Copyright 2016 BMJ Publishing Group. All rights reserved. For permission to reuse any of this content visit

http://group.bmj.com/group/rights-licensing/permissions.

BMJ Case Report Fellows may re-use this article for personal use and teaching without any further permission.

Become a Fellow of BMJ Case Reports today and you can:

- Submit as many cases as you like

- Enjoy fast sympathetic peer review and rapid publication of accepted articles

- Access all the published articles

- Re-use any of the published material for personal use and teaching without further permission

For information on Institutional Fellowships contact consortiasales@bmjgroup.com

Visit casereports.bmj.com for more articles like this and to become a Fellow 